\title{
Desert shrub stemflow and its significance in soil moisture replenishment
}

\author{
X.-P. Wang ${ }^{1,2}$, Z.-N. Wang ${ }^{1}$, R. Berndtsson ${ }^{2}$, Y.-F. Zhang ${ }^{1}$, and Y.-X. Pan ${ }^{1}$ \\ ${ }^{1}$ Shapotou Desert Research and Experiment Station, Cold and Arid Regions Environmental and Engineering Research \\ Institute, Chinese Academy of Sciences, Lanzhou 730000, China \\ ${ }^{2}$ Department of Water Resources Engineering, Lund University, 22100 Lund, Sweden
}

Received: 27 March 2010 - Published in Hydrol. Earth Syst. Sci. Discuss.: 2 August 2010

Revised: 7 October 2010 - Accepted: 28 January 2011 - Published: 11 February 2011

\begin{abstract}
Stemflow of xerophytic shrubs represents a significant component of water replenishment to the soil-root system influencing water utilization of plant roots at the stand scale, especially in water scarce desert ecosystems. In this study, stemflow of Caragana korshinskii was quantified by an aluminum foil collar collection method on re-vegetated sand dunes of the Shapotou restored desert ecosystem in northwestern China. Time domain reflectometry probes were inserted horizontally at 20 different soil profile depths under the $C$. korshinskii shrub to monitor soil moisture variation at hourly intervals. Results indicated that $2.2 \mathrm{~mm}$ precipitation was necessary for the generation of stemflow for C. korshinskii. Stemflow averaged $8 \%$ of the gross precipitation and the average funnelling ratio was as high as 90 . The soil moisture in the uppermost soil profile was strongly correlated with individual rainfall and the stemflow strengthened this relationship. Therefore, it is favourable for the infiltrated water redistribution in the deeper soil profile of the root zone. Consequently, stemflow contributes significantly to a positive soil moisture balance in the root zone and the replenishment of soil moisture at deeper soil layers. This plays an important role in plant survival and the general ecology of arid desert environments.
\end{abstract}

\section{Introduction}

Water scarcity is the greatest in semiarid and arid regions because of limited supplies and increasing demand due to greater population growth relative to more humid regions (e.g., Vörösmarty et al., 2000). Thus, precipitation plays an important role in water-scarce arid environments. The pattern of transferring limited rainfall to the soil will regulate

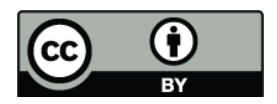

Correspondence to: X.-P. Wang (xpwang@lzb.ac.cn) the soil water replenishment and utilization of plant roots. Stemflow can concentrate the rainfall intercepted by leaves and branches to the plant stem. Since water resources are limited in arid lands, stemflow can be an important source of soil moisture replenishment (Tromble, 1987). Návar and Bryan (1990) calculated that stemflow input to the soil area around three semiarid shrub stems in northeastern Mexico represented a water input that was five times higher than by other areas below the shrub canopies. Other arid shrubs are also adapted to divert rainfall to the base of their stems as stemflow where it subsequently infiltrates the soil and remains available for plant uptake at deeper soil layers (Pressland, 1976; Nulsen et al., 1986; Návar, 1993; Martinez-Meza and Whitford, 1996; Li et al., 2008). Levia and Frost (2003) provided a thorough review of the quantitative and qualitative importance of stemflow in forests as well as in agricultural environments.

Herwitz (1986) suggested that the quantitative importance of stemflow at the point scale can be expressed as a funnelling ratio, $F$ :

$F=\frac{V_{\mathrm{SF}}}{A_{\mathrm{B}} \times P / 10}$

where $V_{\mathrm{SF}}$ is the volume $\left(\mathrm{cm}^{3}\right)$ of stemflow, $A_{\mathrm{B}}$ is the trunk basal area $\left(\mathrm{cm}^{2}\right)$ and $P$ is the depth equivalent of gross incident precipitation (mm). The product $A_{\mathrm{B}} \times P / 10$ provides the volume $\left(\mathrm{cm}^{3}\right)$ of water that would have been caught by a rain gauge having an opening equal to that of the trunk basal area. Thus, $F$ represents the ratio of the amount of precipitation delivered to the base of the shrubs to the rainfall that would have reached the ground if the shrub were not present. Many studies in arid environments indicate that the funnelling ratio can be $>10$ and in some cases $\gg 10$ (e.g., Návar, 1993; Carlyle-Moses, 2004; Li et al., 2008). Consequently, the water volume of the stemflow that entres the soil around the stem will be greater than that of the corresponding rainfall due to the high funnelling ratio.

Published by Copernicus Publications on behalf of the European Geosciences Union. 
Table 1. Descriptive statistics (mean \pm standard deviation) of branches and canopy projection of the C. corshinskii shrubs used in the experiments.

\begin{tabular}{lrccccr}
\hline & \multicolumn{5}{c}{ Shrub branch } & Canopy projection \\
\cline { 2 - 5 } & Number & Diameter $(\mathrm{cm})$ & Length $(\mathrm{cm})$ & Height $(\mathrm{cm})$ & Angle $\left({ }^{\circ}\right)^{\mathrm{a}}$ & 80425 \\
\hline shrub 1 & 20 & $1.6 \pm 0.2$ & $184 \pm 11.1$ & $51.4 \pm 32.0$ & $62.0 \pm 18.0$ & 28274 \\
shrub 2 & 11 & $2.0 \pm 0.3$ & $223 \pm 38.0$ & $72.0 \pm 16.4$ & $65.9 \pm 4.5$ & 22619 \\
shrub 3 & 10 & $1.6 \pm 0.7$ & $138 \pm 30.6$ & $43.3 \pm 12.1$ & $63.8 \pm 8.8$ & 52779 \\
shrub 4 & 14 & $2.0 \pm 0.8$ & $145 \pm 21.8$ & $36.0 \pm 18.2$ & $52.2 \pm 19.5$ & 45239 \\
shrub 5 & 20 & $2.0 \pm 0.8$ & $176 \pm 26.1$ & $52.0 \pm 13.0$ & $66.7 \pm 4.5$ & 20028 \\
shrub 6 & 8 & $1.4 \pm 0.4$ & $158 \pm 27.4$ & $40.0 \pm 14.1$ & $69.0 \pm 11.6$ & 28353 \\
shrub 7 & 6 & $2.2 \pm 0.6$ & $206 \pm 18.2$ & $37.0 \pm 19.2$ & $75.4 \pm 11.0$ & 17868 \\
shrub 8 & 14 & $1.3 \pm 0.3$ & $126 \pm 5.5$ & $30.0 \pm 18.7$ & $65.8 \pm 22.8$ & $36948 \pm 21429$ \\
average & 13 & $1.8 \pm 0.3$ & $170 \pm 34$ & $45.2 \pm 13.2$ & $65.1 \pm 6.6$ & \\
\hline
\end{tabular}

a Angle in degree of the upward branch to the ground surface.

Re-vegetation experiments have been established for more than 50 years in the southeastern fringe of the Tengger Desert, using mainly xerophytic shrubs, such as C. korshinskii, Hedysarum scoparium and Artemisia ordosica. The low water content of desert soils limits the number of shrubs and its stabilization. The effects of both rainfall and soil surface characteristics on soil water replenishment in re-vegetated desert ecosystems have been studied by Wang et al. (2007, 2008). However, the effect of stemflow on infiltration patterns associated with the soil moisture replenishment is almost totally unexplored.

The objectives of the study were to quantify the variation of stemflow of $C$. korshinskii, and to evaluate the stemflow infiltration process in the re-vegetation stabilized semi-arid shrub desert in northwestern China that has changed from a bare to a vegetated soil.

\section{Materials and methods}

\subsection{Study site description}

The study was conducted at Shapotou Desert Research and Experiment Station $\left(37^{\circ} 27^{\prime} \mathrm{N}, 104^{\circ} 57^{\prime} \mathrm{E}, 1339 \mathrm{~m}\right.$ a.s.1.) on the southeastern fringe of the Tengger Desert, where successful re-vegetation experiments have been carried out since 1956 using a combination of windbreaks, straw checkerboard barriers and planted xerophytic shrubs. The natural climatic conditions have been described in detail by Wang et al. (2004). Precipitation is the only source of soil water in this area. Based on the analysis of a 50-year time series of meteorological data collected at the Shapotou Desert Research and Experiment Station, operated by the Chinese Academy of Sciences, mean annual precipitation is $191 \mathrm{~mm}$. About $80 \%$ of this rainfall occurs between June and September with a coefficient variation as high as $46 \%$. The annual poten- tial evaporation is about $3000 \mathrm{~mm}$. The mean daily temperature of the coldest month (January) is $-6.1^{\circ}$ and that of the warmest month (July) is $24.7^{\circ}$. The mean relative humidity varies from $31 \%$ (April) to 54\% (August). The first frost occurs in late September and the last frost ends in midApril. The area has large and dense reticulate dune chains. The main dune crest migrates southeastward at a velocity of $0.3-0.6 \mathrm{my}^{-1}$. The dune sand consists of $99.7 \%$ fine sand with grain size between 0.05 and $0.25 \mathrm{~mm}, 0.1 \%$ of silt with a grain size between 0.002 and $0.05 \mathrm{~mm}$, and $0.2 \%$ of clay with a grain size less than $0.002 \mathrm{~mm}$ (Wang et al., 2008). The soil is loose with impoverished mobile sand and a consistent moisture content ranging from 3-4\% and classified as Typic Psammaquent (Berndtsson et al., 1996). The depth to groundwater is between 50 and $80 \mathrm{~m}$ and, therefore, groundwater is unable to support the natural vegetation.

\subsection{Experimental set-up and data collection}

Stemflow was measured for eight fully mature plants of 20-year-old C. korshinskii that were planted in 1989 as 1year-old seedlings in the water balance experimental field of Shapotou. The number, length, height and diameter of the branches were measured, and the branch-angle was calculated by the branch height from the ground surface to the tip of the branch vertically and the distance of the branch away from the stem horizontally. The stem basal area in Eq. (1) is the sum of the basal area of each branch. The shrub canopy projective area was calculated by taking the longest and shortest diameters through the centre of the fullest part of the canopy (Table 1). For the stemflow collection, fine sandpaper was used to burnish the selected branch surface about $10 \mathrm{~cm}$ above the ground. Then, stemflow was collected using collars constructed from flexible aluminum foil plates that were fitted around the entire circumference of the branches. Each collar was sealed to the branch using all weather silicon 


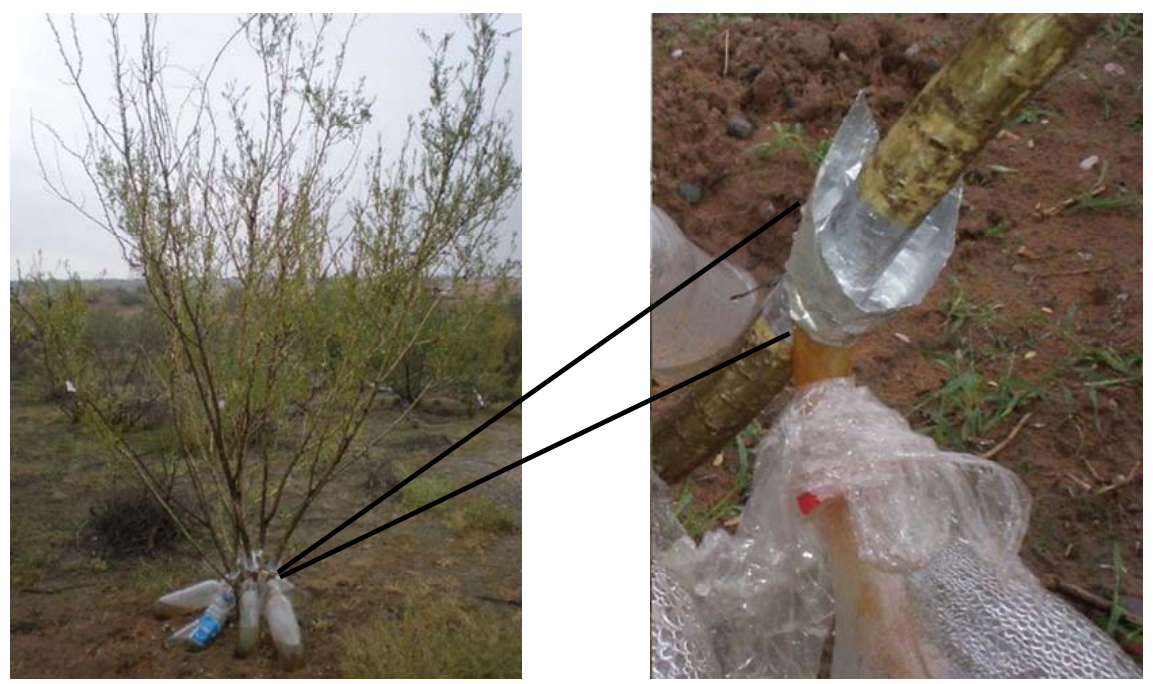

Fig. 1. Photographs showing method of collecting stemflow for C. korshinskii.

caulking. Stemflow water was delivered from the collar to a collection bottle via a $1.5 \mathrm{~cm}$ aperture plastic hose (Fig. 1). Stemflow was measured by a graduated cylinder for each branch after each rainfall event and summarized for a single shrub. The stemflow volume of each shrub was divided by its canopy area to calculate the stemflow depth on a stand basis. The stemflow measurements under natural rainfall conditions were carried out according to the Dunkerley (2008) standard for identifying individual rainfall events in accordance with the condition of dry desert environments in Shapotou, where an individual rainfall event was defined as a rainfall separated by a dry interval of at least $6 \mathrm{~h}$.

For measuring the soil moisture, time domain reflectometry (TDR) probes (Model 6050X1, Trase System I, Soilmoisture Equipment Corp., USA) were inserted at twenty depths of $5,10,15,20,25,30,35,40,45,50,60,70,80,90,100$, $120,140,160,180$, and $200 \mathrm{~cm}$ on different plant locations from the stemflow measurements. The probe has three $20 \mathrm{~cm}$ rods spaced $2.5 \mathrm{~cm}$ apart. For probe installation, a pit, $20 \mathrm{~cm}$ away from the stem, was dug into the soil with a sufficient width to be able to insert the probes. The probes were inserted into the soil through the side of the unaltered pit and placed horizontally in the direction of the shrub site. Once the probes had been inserted, the pit was carefully refilled, avoiding perturbations as far as possible, and the surface was contoured similar to the surrounding slope. To reduce the influence of the terrain, shrubs of $C$. korshinskii growing on a flat ground were selected. The experiment was set up in February 2008 and soil moisture measurements associated with the stemflow measurements were done between July and October 2008.
The TDR instrument measures volumetric soil moisture between $0 \%$ and $100 \%$, with an accuracy of $\leq 0.1 \%$. The wetting front location and cumulative infiltration are detected by measuring changes in soil moisture in the soil profile (e.g., Noborio et al., 1996; Wang et al., 2007). Noborio et al. (1996) found that the cumulative infiltration estimated by TDR compared favourably with observed infiltration, and the distance to the wetting front from soil surface estimated by TDR agreed well with the observed values. All data were collected simultaneously during and directly following rain events sufficient to trace wetting front changes at hourly intervals.

According to the above, volumetric soil water content was measured by TDR probes matching the different depth of the soil profile. Hence, water balances could be calculated according to the position of TDR probes. Based on the principle of soil water balance, the cumulative infiltration could be described as:

$I=10\left(\theta_{\mathrm{e}}-\theta_{\mathrm{i}}\right) Z_{\mathrm{f}}$

$\Delta S=\sum_{d=1}^{20} I_{\mathrm{d}}$

where $\theta_{\mathrm{e}}$ is the volumetric soil water content $\left(\mathrm{cm}^{3} \mathrm{~cm}^{-3}\right)$ at the end stage, $\theta_{\mathrm{i}}$ is initial volumetric soil water content $\left(\mathrm{cm}^{3} \mathrm{~cm}^{-3}\right), Z_{\mathrm{f}}$ is infiltration depth below ground $(\mathrm{cm}), \Delta S$ is the soil moisture increment $(\mathrm{mm})$, and $I_{\mathrm{d}}$ is cumulative infiltration at a specific depth section ( $\mathrm{mm})$.

A standard automatic rain gauge with a resolution of $0.1 \mathrm{~mm}$ (Adolf Thies GMVH \& Co. KG, Germany) was installed at an open area $50 \mathrm{~m}$ from the study plot, to obtain the amount and intensity of rainfall. 


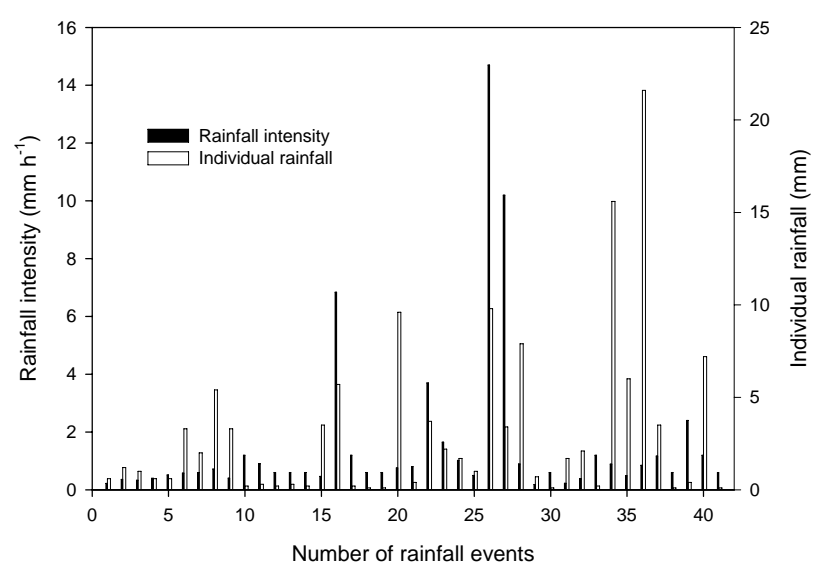

Fig. 2. Rainfall intensity and rainfall amount for 41 individual events during 2008 at the experimental site.

\section{Results}

\subsection{Rainfall characteristics during the experimental period}

There were a total of 41 rainfall events in 2008, resulting in an annual rainfall of $127.8 \mathrm{~mm}$ with an average event rainfall intensity of $1.5 \mathrm{~mm} \mathrm{~h}^{-1}$ ranging from 0.2 to $14.7 \mathrm{~mm} \mathrm{~h}^{-1}$ and an average individual rainfall of $3.1 \mathrm{~mm}$ ranging from 0.1 to $21.6 \mathrm{~mm}$ (Fig. 2). There was no rainfall in March, May, November and December 2008, and it was a relatively dry year compared to the long-term average rainfall of $191 \mathrm{~mm}$. Stemflow was monitored during a total of 14 rainfall events among the 41 rainfall events numbered 15, 16, 20, 22, 23, 24, $26,27,28,32,35,36,37$, and 40 in Fig. 2, corresponding to the dates of 13, 17, 30-31 July, 6, 8, 9, 26, 28, 28-29 August, $8,22-23,26-27$ September and 3, 21-22 October 2008. The 14 events produced a total of $87.8 \mathrm{~mm}$ rainfall, which accounted for $69 \%$ of the annual rainfall in amount and $34 \%$ in event number (Fig. 2). These consisted of the main rainfall events varying between 1.7 and $21.6 \mathrm{~mm}$ in 2008 . The maximum rainfall intensity in $10 \mathrm{~min}\left(I_{10}\right)$ was $33 \mathrm{~mm} \mathrm{~h}^{-1}$, and the mean rainfall intensities ranged from 0.5 to $14.7 \mathrm{~mm} \mathrm{~h}^{-1}$ (Fig. 2). On the contrary, there were 23 rain events that accounted for $56 \%$ in event number that contributed less than $10 \%$ to the annual rainfall amount $(12.3 \mathrm{~mm}$ in total) with no stemflow occurring. Note that the rainfall event numbered 34 occurred on the midnight of 21 September at 22:50 LT to 22 September at 16:30 LT. This event had a rain depth of $15.6 \mathrm{~mm}$ that was excluded from the analysis because the collection bottles overflowed before the data collection. There were no indications that the observed rainfall during the experimental period was not typical for the area. Thus, the observations in the present study are relevant for the estimation of stemflow and ratio to rainfall and likely representative for larger areas.

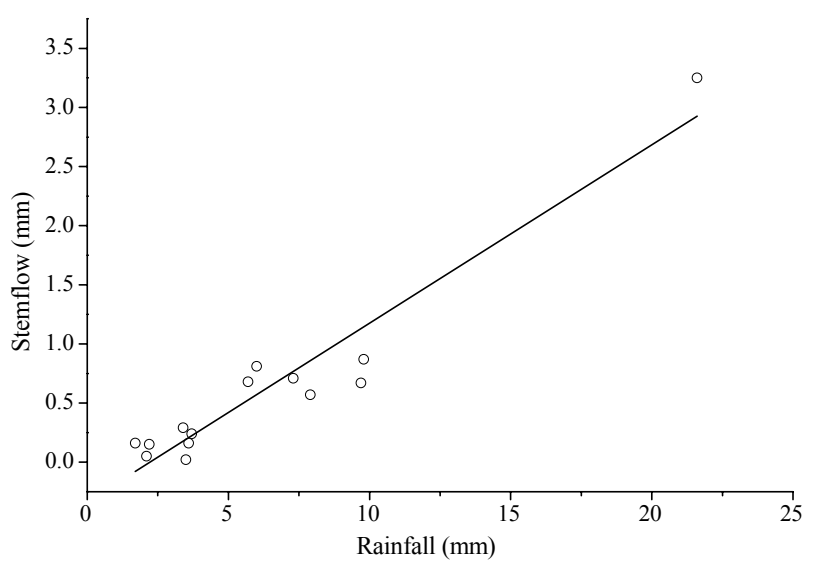

Fig. 3. Relationship between individual rainfall and stemflow for $C$. korshinskii.

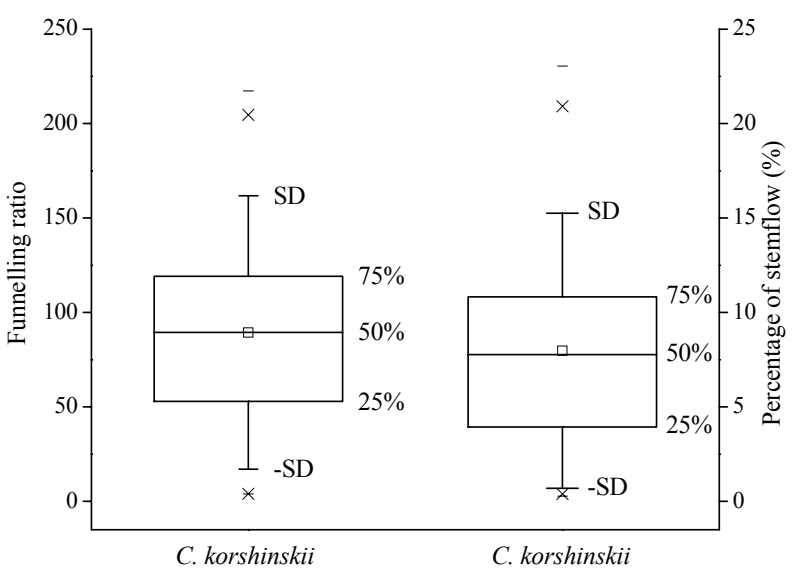

Fig. 4. Box-and-whisker diagrams showing median, 25, 50, 75 percentiles and standard deviation for individual funnelling ratio and stemflow percentage for C. korshinskii. ( $\square$ ) represents mean value, $(-)$ maximum and minimum value and $(\times)$ are 1 st and 99th percentiles.

\subsection{Stemflow properties}

Stemflow increased approximately linearly with cumulative rainfall (Fig. 3). Linear regression between individual gross rainfall and individual stemflow was:

$\mathrm{SF}=0.151 P_{\mathrm{G}}-0.3346 \quad\left(R^{2}=0.913, p<0.001\right)$

where $P_{\mathrm{G}}$ is the gross rainfall $(\mathrm{mm})$ and $\mathrm{SF}$ is the stemflow (mm) from the $C$. korshinskii plant. The rainfall threshold for stemflow generation was $2.2 \mathrm{~mm}$ according to linear regression for C. korshinskii. Stemflow accounted for $7.9 \pm 1.3 \%$ (mean \pm standard error) of rainfall and average funnelling ratio was 89.8 ranging from 6.4 to 168.5 (Fig. 4). The average funnelling ratio was close to 60 when rainfall was less than $6 \mathrm{~mm}$ and close to 120 when rainfall was larger than $6 \mathrm{~mm}$. There was a great variability in the funnelling ra- 

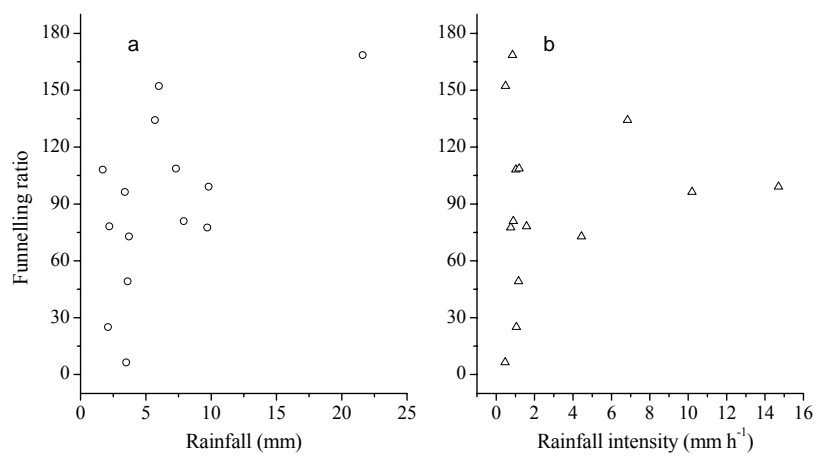

Fig. 5. Relationship between funnelling ratio and rainfall amount (a) and rainfall intensity (b).

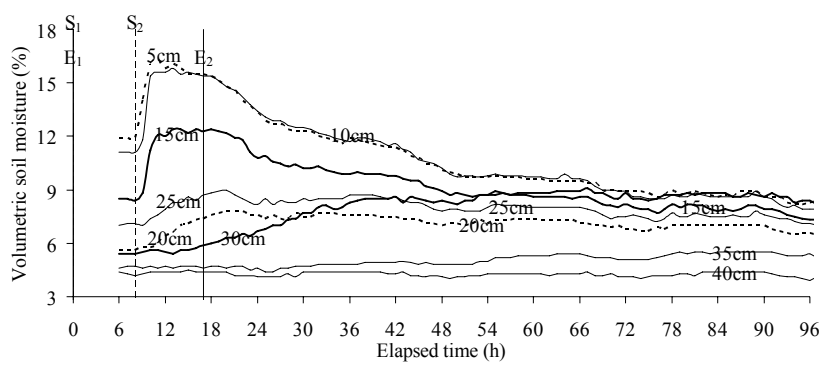

Fig. 6. The wetting front advance from 14:00 LT of 28 August to 14:00 LT of 1 September. Vertical lines of paired S and E represent the start (dashed line) and end (solid line) of individual rainfall, respectively.

tio when rainfall intensity was less than $6 \mathrm{~mm} \mathrm{~h}^{-1}$. When rainfall intensity was greater than $6 \mathrm{~mm} \mathrm{~h}^{-1}$, funnelling ratio tended to be stable with increasing rainfall intensity (Fig. 5).

\subsection{Advance of wetting front}

The wetting front was determined by evaluating the difference in soil moisture content for consecutive soil layers. The change in soil moisture with time from 14:00 LT, 28 August, to 14:00 LT, 1 September, and 00:00 LT, 22 September, to 00:00 LT, 1 October, is shown in Figs. 6 and 7. As seen from the figures, infiltrated water reached deeper soil depths after several hours from the start of individual rainfall events. At depths greater than $30 \mathrm{~cm}$, the change of soil moisture often lagged $20-24 \mathrm{~h}$ behind that of the top soil profile. For a consecutive series of large rainfall events with a cumulative rainfall of $42.5 \mathrm{~mm}$ (from 00:00 LT of 22 September to 21:00 LT of 26 September), the wetting front reached a depth of $90 \mathrm{~cm}$. For a consecutive series of small rainfall events with a cumulative rainfall of $11.3 \mathrm{~mm}$ (from 14:00 LT of 28 August to 07:00 LT of 29 August), the wetting front could not be noticed at $40 \mathrm{~cm}$ depth. The soil moisture increase at the top layer $0-10 \mathrm{~cm}$ occurred at exactly the same time as the start of the rainfall. The soil moisture in the upper soil profile

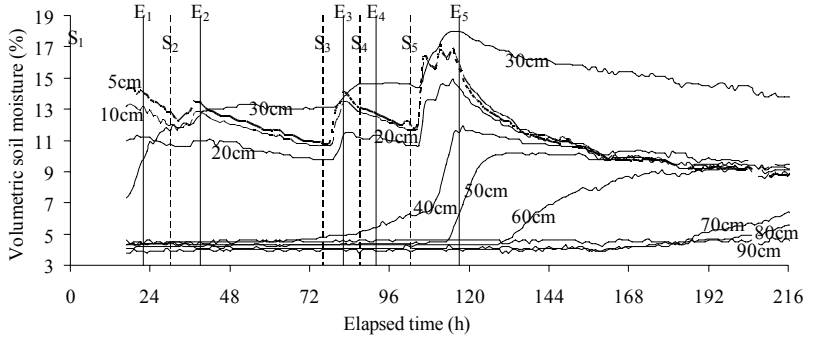

Fig. 7. The wetting front advance from 00:00 LT of 22 September to 00:00 LT of 1 October. Vertical lines of paired S and E represent the start (dashed line) and end (solid line) of individual rainfall, respectively.

fluctuated with the variation of rainfall intensity (Figs. 2, 6, and 7). However, there were no noticeable changes in soil moisture at the top soil profile for small-sized rainfall events at 72 and $216 \mathrm{~h}$ (Fig. 7). The soil moisture at the top layer of less than $20 \mathrm{~cm}$ declined quickly with the cessation of rainfall, though at $30 \mathrm{~cm}$ it declined slowly from a relatively large value. A similar trend was seen for soil moisture changes at soil depths larger than $30 \mathrm{~cm}$, soil moisture increased to a maximum after rainfall events and then declined slowly. Changes in soil moisture after rainfall were generally only noticed at depths of $0-55 \mathrm{~cm}$.

The rainfall amount was compared with the total change of soil moisture at consecutive depths in the $0-55 \mathrm{~cm}$ soil (Table 2). For small-sized rainfall events (about $2.0 \mathrm{~mm}$ ), no soil moisture change was observed. However, there was a clear increase in soil water when a small-sized rainfall event followed a larger rainfall event (e.g., 23 September). Mediumsized rainfall events (about $4 \mathrm{~mm}$ ) could effectively infiltrate the soil profile and affected the cumulative infiltration at shallow soil layers. Also, the total soil moisture increase almost equalled the corresponding rainfall amount. Under relatively large rainfall conditions(about $14 \mathrm{~mm}$ ), the soil moisture increase was greater than the corresponding rainfall amount.

\section{Discussion}

The experiments were done on eight $C$. korshinskii shrubs with plenty of branches that varied from 8 to 20, averaging 13 for each shrub (Table 1). The stem traits, such as the diameter, length and the stretch angles of the branches together with the canopy projection, were identical with typical mature $C$. korshinskii shrubs in the study area (Wang et al., 2005). The angle of the upward branches to the ground surface that averaged around $65^{\circ}$ classified the shrub shape to approximately an inverted cone, characterised by a relatively uniform upward branch stretch orientation (Table 1), indicating the applicable methodology for stemflow measurement that was used in the present study. 
Table 2. Changes in cumulative infiltration $(\mathrm{mm})$ at different soil layers.

\begin{tabular}{lrccrrrr}
\hline & 29 Aug & 8 Sep & 9 Sep & 23 Sep & 25 Sep & 26 Sep & 3 Oct \\
\cline { 2 - 8 } Rainfall $(\mathrm{mm})$ & 7.9 & 1.6 & 2.0 & 4.0 & 7.5 & 14.0 & 3.5 \\
\hline Layer 0-5 cm & 1.75 & 0 & 0 & 0.40 & 1.65 & 1.60 & 0.05 \\
Layer 5-10 cm & 2.15 & 0 & 0 & 0.40 & 1.40 & 1.80 & 0 \\
Layer $10-15 \mathrm{~cm}$ & 1.95 & 0 & 0 & 0.55 & 1.05 & 1.85 & 0 \\
Layer $15-20 \mathrm{~cm}$ & 1.00 & 0 & 0 & 0.15 & 0.75 & 1.70 & 0 \\
Layer $20-25 \mathrm{~cm}$ & 0.85 & 0 & 0 & 0.30 & 0.45 & 1.95 & 0 \\
Layer $25-30 \mathrm{~cm}$ & 0.30 & 0 & 0 & 0.30 & 0.30 & 1.70 & 0 \\
Layer $35-40 \mathrm{~cm}$ & 0 & 0 & 0 & 0.50 & 0.15 & 1.95 & 0 \\
Layer $40-45 \mathrm{~cm}$ & 0 & 0 & 0 & 0 & 0.05 & 2.85 & 0 \\
Layer $45-50 \mathrm{~cm}$ & 0 & 0 & 0 & 0 & 0 & 2.60 & 0 \\
Layer $50-55 \mathrm{~cm}$ & 0 & 0 & 0 & 0 & 0 & 1.25 & 0 \\
Soil moisture & 8.00 & 0 & 0 & 2.60 & 5.80 & 19.25 & 0.05 \\
increase $(\mathrm{mm})$ & & & & & & & \\
\hline
\end{tabular}

For C. korshinskii, rainfall of at least $2.2 \mathrm{~mm}$ was necessary to initiate stemflow according to linear regression. This threshold is consistent with thresholds reported by previous studies in arid areas (e.g., Martinez-Meza and Whitford, 1996; Návar, 1993; Enright, 1987; Li et al., 2008). Stemflow accounted for $7.9 \%$ of the gross rainfall and the average funnelling ratio was 89.8 . For large rainfall events $(>10 \mathrm{~mm})$, stemflow concentrated more water to the root zone. Thus, the efficiency of water infiltration in soil is enhanced and soil moisture increase is larger than the corresponding rainfall.

The funnelling ratio varied greatly for different rainfall events, depending on the rainfall amount and rainfall intensity. Funnelling ratios have been found to be greater than 10, and in some cases, far greater than 10 (e.g., Návar, 1993; Carlyle-Moses, 2004; Li et al., 2008). Our studies showed that there can be ten or even a hundred times the rainwater amount that may reach the root area by stemflow as compared to an open area. The excess water effectively enhances the moisture of the upper soil layer, and then a greater water potential gradient is formed between the upper wet soil layer and the deeper dry soil profile. Consequently, the probability of water infiltrating to the deeper soil becomes higher around shrub stems. Also, stemflow water in desert shrubs may be assumed to be distributed to a deep soil layer by preferential flow along root channels (e.g., Martinez-Meza and Whitford, 1996). For relatively large cumulative rainfall of $42.5 \mathrm{~mm}$ (from 00:00 LT of 22 September to 21:00 LT of 26 September), the wetting front reached a depth of $90 \mathrm{~cm}$ (Fig. 7). Hence, stemflow efficiently helps water to infiltrate to deeper soil layers that can be effectively utilized by the shrub plants.

Stemflow water can effectively refill the soil profile and increase the cumulative infiltration for medium- and largesized rainfall. According to previous research, from the point of view of soil moisture replenishment in this particular artificially re-vegetated sand dune area, only when an individual rainfall event is $>8 \mathrm{~mm}$ (Chen, 1991; Zhao, 1991), with an average rainfall intensity $>0.5 \mathrm{~mm} \mathrm{~h}^{-1}$ (Wang et al., 2008), it is an effective rainfall for the vegetated soil. While for the stem basal area of $C$. korshinskii, the corresponding threshold value is about $4 \mathrm{~mm}$ (Table 2, on 23 September 2008) which replenish the soil moisture at the profile deeper than $5 \mathrm{~cm}$, comparing it to the rainfall of $3.5 \mathrm{~mm}$ that limited the soil moisture increment within the upper layer of $5 \mathrm{~cm}(\mathrm{Ta}-$ ble 2, on 3 October 2008). Therefore, stemflow doubled the effective rainfall in terms of the soil moisture replenishment in the root zone below $5 \mathrm{~cm}$ depth. Stemflow inputs depend not only on rainfall characteristics (such as rainfall amount, intensity and duration), but also on meteorological conditions, seasonality and shrub canopy structure. On the other hand, there are interspecific and intraspecific differences among and within shrub species (e.g., Levia and Frost, 2003; Llorens and Domingo, 2007). Infiltration is also influenced by soil surface characteristics (such as microtopography, cracking, surface sealing and crusting), soil physical properties (such as bulk density, organic matter and particle size distribution), and characteristics of the vegetation (such as plant biomass and cover) (e.g., Eldridge et al., 2000; Wang et al., 2007). For our study area, the fate of stemflow is probably mainly affected by the properties of the biological soil crust formation that develops around the shrub stems. From our studies, we can conclude that it is important to quantify the stemflow when designing shrub plantations in arid areas. Stemflow contributes efficiently to the water availability for the plant roots. Consequently, stemflow is an important part of the local water balance around shrub species.

\section{Conclusions}

A better understanding of the stemflow variability and its contribution to soil moisture is essential in the re-vegetation efforts of inhabited arid regions. An antecedent precipitation of $2.2 \mathrm{~mm}$ is needed for the initiation of stemflow of the shrub stand. Owing to the high values of funnelling ratio (e.g., 90) of the studied species, the shrub plants can concentrate water flux to the stem basal area. A threshold value corresponding to rainfall of $4 \mathrm{~mm}$ is required for stemflow water to replenish the soil moisture at the stem basal area. Thus, from the point view of the funnelling ratio and cumulative infiltration, we may conclude that especially for the studied area, where rainfall events typically are small and of low intensity, stemflow is of immense importance to sustain the ecosystem close to and around shrubs at the stand scale.

Acknowledgements. The experiment is jointly supported by the CAS Action Plan for West Development Programme (KZCX2XB2-09), the National Natural Science Foundation of China (31070415) and the Western (China) Lightening Programme for Joint Scholars of Talent Training of Chinese Academy of Sciences. This publication was produced during xpw's scholarship period at Lund University thanks to a Swedish Institute scholarship.

Edited by: M. Menenti 


\section{References}

Berndtsson, R., Nodomi, K., Yasuda, H., Persson, T., Chen, H., and Jinno, K.: Soil water and temperature patterns in an arid desert dune sand, J. Hydrol., 185, 221-240, 1996.

Carlyle-Moses, D. E.: Throughfall, stemflow, and canopy interception loss fluxes in a semi-arid Sierra Madre Oriental matorral community, J. Arid Environ., 58, 181-202, 2004.

Chen, W. R.: Water balance in the revegetated area along the railway in Shapotou area, in: Study on Shifting Sand Control in Shapotou Region of the Tengger Desert, edited by: Shapotou Desert Experimental Research Station, Chinese Academy of Sciences, Ningxia People's Publishing House, Yinchuan, 66-75, 1991.

Dunkerley, D.: Identifying individual rain events from pluviograph records: a review with analysis of data from an Australian dryland site, Hydrol. Process., 22, 5024-5036, 2008.

Eldridge, D. J., Zaady, E., and Shachak, M.: Infiltration through three contrasting biological soil crusts in patterned landscape in the Negev, Israel, Catena, 40, 323-336, 2000.

Enright, N. J.: Stemflow as a nutrient source for nikau palm (Rhopalostylis sapida) in a New Zealand forest, Aust. J. Ecol., 12, 17-24, 1987.

Herwitz, S. R.: Infiltration-excess caused by stemflow in a cycloneprone tropical rainforest, Earth Surf. Proc. Land, 11, 401-412, 1986.

Levia, D. F. and Frost, E. E.: A review and evaluation of stemflow literature in the hydrologic and biogeochemical cycles of froested and agricultural ecosystems, J. Hydrol., 274(1-4), 1-29, 2003.

Li, X. Y., Liu, L. Y., Gao, S. Y., Ma, Y. J., and Yang, Z. P.: Stemflow in three shrubs and its effect on soil water enhancement in semiarid loess region of China, Agric. Forest Meteorol., 148(10), 1501-1507, 2008.

Llorens, P. and Domingo, F.: Rainfall partitioning by vegetation under Mediterranean conditions, A review of studies in Europe, J. Hydrol., 335, 37-54, 2007.

Martinez-Meza, E. and Whitford, W. G.: Stemflow, throughfall and channelization of stemflow by roots in three Chihuahuan desert shrubs, J. Arid Environ., 32, 271-287, 1996.
Návar, J.: The causes of stemflow variation in three semiarid growing species of northeastern Mexico, J. Hydrol., 145, 165-190, 1993.

Návar, J. and Bryan, R. B.: Interception loss and rainfall redistribution by three semi-arid growing shrubs in northeastern Mexico, J. Hydrol., 115, 51-63, 1990.

Noborio, K., McInnes, K. J., and Heilman, J. L.: Measurements of cumulative infiltration and wetting front location by time domain reflectometry, Soil Sci., 161, 480-483, 1996.

Nulsen, R. A., Bligh, K. J., Baxter, I. N., Solin, E. J., and Imrie, D. H.: The fate of rainfall in a mallee and heath vegetated catchment in southern Western Australia, Aust. J. Ecol, 11, 361-371, 1986.

Pressland, A. J.: Soil moisture redistribution as affected by throughfall and stemflow in an arid zone shrub community, Aust. J. Bot., 24, 641-649, 1976.

Tromble, J. M.: Water interception by two arid land shrubs, J. Arid Environ., 15, 65-70, 1987.

Vörösmarty, C. J., Green, P., Salisbury, J., and Lammers, R. B.: Global water resources: vulnerability from climate change and population growth, Science, 289, 284-288, 2000.

Wang, X. P., Berndtsson, R., Li, X. R., and Kang, E. S.: Water balance change for a re-vegetated xerophyte shrub area, Hydrol. Sci. J. 49, 283-295, 2004.

Wang, X. P., Li, X. R., Zhang, J. G., Zhang, Z. S., and Berndtsson, R.: Measurement of rainfall interception by xerophytic shrubs in re-vegetated sand dunes, Hydrol. Sci. J., 50, 897-910, 2005.

Wang, X. P., Li, X. R., Xiao, H. L., Berndtsson, R. and Pan, Y. X.: Effects of surface characteristics on infiltration patterns in an arid shrub desert, Hydrol. Process., 21, 72-79, 2007.

Wang, X. P., Cui, Y., Pan, Y. X., Li. X. R., Yu, Z., and Young, M. H.: Effects of rainfall characteristics on infiltration and redistribution patterns in revegetation-stabilized desert ecosystems, J. Hydrol., 358, 134-143, 2008.

Zhao, X. L.: Problems of revegetation on sand dunes in Shapotou area, in: Study on Shifting Sand Control in Shapotou Region of the Tengger Desert, edited by: Shapotou Desert Experimental Research Station, Chinese Academy of Sciences, Ningxia People's Publishing House, Yinchuan, 27-57, 1991. 